\title{
Arqueología de Colquioc, valle del río Purísima, cuenca media del Fortaleza, Áncash
}

Recibido: 30/04/2020

Aprobado: 27/06/2020

Publicado: $25 / 08 / 2020$
Pieter D. van Dalen Luna

Universidad Nacional Mayor de San Marcos <pvandalenl@unmsm.edu.pe>

Luis Reymundo Lume Universidad Nacional Mayor de San Marcos <ranq.king@gmail.com>

Joe Huamaní Perlacios Universidad Nacional Mayor de San Marcos <johuper@hotmail.com>

\section{RESUMEN}

En el presente artículo presentamos los resultados de las investigaciones arqueológicas desarrolladas en el anexo de Colquioc, distrito del mismo nombre. Las prospecciones arqueológicas han permitido registrar sitios arqueológicos hasta hoy desconocidos para la arqueología, de los periodos Horizonte Temprano, conformado por estructuras piramidales; pequeńas unidades domésticas y áreas funerarias del Periodo Intermedio Tardío; y el pueblo viejo de datación Colonial, correspondiente al pueblo de fundación reduccional del primer siglo de dominación hispana. La zona de Colquioc adquirió una importancia estratégica en periodos prehispánicos por su ubicación, junto a la confluencia de los ríos Fortaleza y Purísima, siendo punto de encuentro de diversos grupos a través del tinkuy.

Palabras clave: arqueología, Ancash, cuenca del río Fortaleza, arqueología del territorio, arqueología histórica.

\section{Colquioc archeology, Purisima river valley, middle basin of the Fortaleza, Ancash}

\begin{abstract}
In this article we present the results of the archaeological investigations carried out in the Colquioc annex, district of the same name. Archaeological surveys have allowed to record archaeological sites hitherto unknown to archeology, from the Early Horizon periods, made up of pyramidal structures; small domestic units and burial areas of the Late Intermediate Period; and the old town of Colonial dating, corresponding to the town of reduction foundation of the first century of Hispanic domination. The Colquioc area acquired strategic importance in pre-Hispanic periods due to its location, next to the confluence of the Fortaleza and Purisima rivers, being a meeting point for various groups through the Tinkuy.
\end{abstract}

KeYwords: archeology, Ancash, Fortaleza river basin, territory archeology, historical archeology. 


\section{Introducción}

$\square$ ntre los años 2015 y 2019 hemos venido realizando investigaciones arqueológicas en el ámbito de la provincia de Bolognesi, en el departamento de Ancash, con el objetivo de determinar las características de las ocupaciones prehispánicas. El año 2016 a través del Vicerrectorado de Investigación de la Universidad Nacional Mayor de San Marcos mediante sus Proyectos Multidisciplinarios de Investigación, se ejecutó el proyecto: "Catastro e inventario del patrimonio cultural de la provincia de Bolognesi, departamento de Ancash", con código PMI2016K01. En el marco de este proyecto de investigación se realizaron trabajos de prospección y registro de los sitios arqueológicos de los 15 distritos que conforman esta provincia, entre estos el distrito de Colquioc, ubicado en la margen izquierda del valle medio del río Fortaleza.

El distrito de Colquioc, con su capital Chasquitambo, es la puerta de entrada al departamento de Ancash, situándose en el límite de Ancash con el distrito limeño de Paramonga (provincia de Barranca). Su ubicación estratégica, en el valle medio del río Fortaleza, de buen clima (cálido) y zona obligada de paso para todas las personas que se dirigen hacia la Costa desde el centro y sur del departamento de Ancash, le ha dado a este distrito una importancia

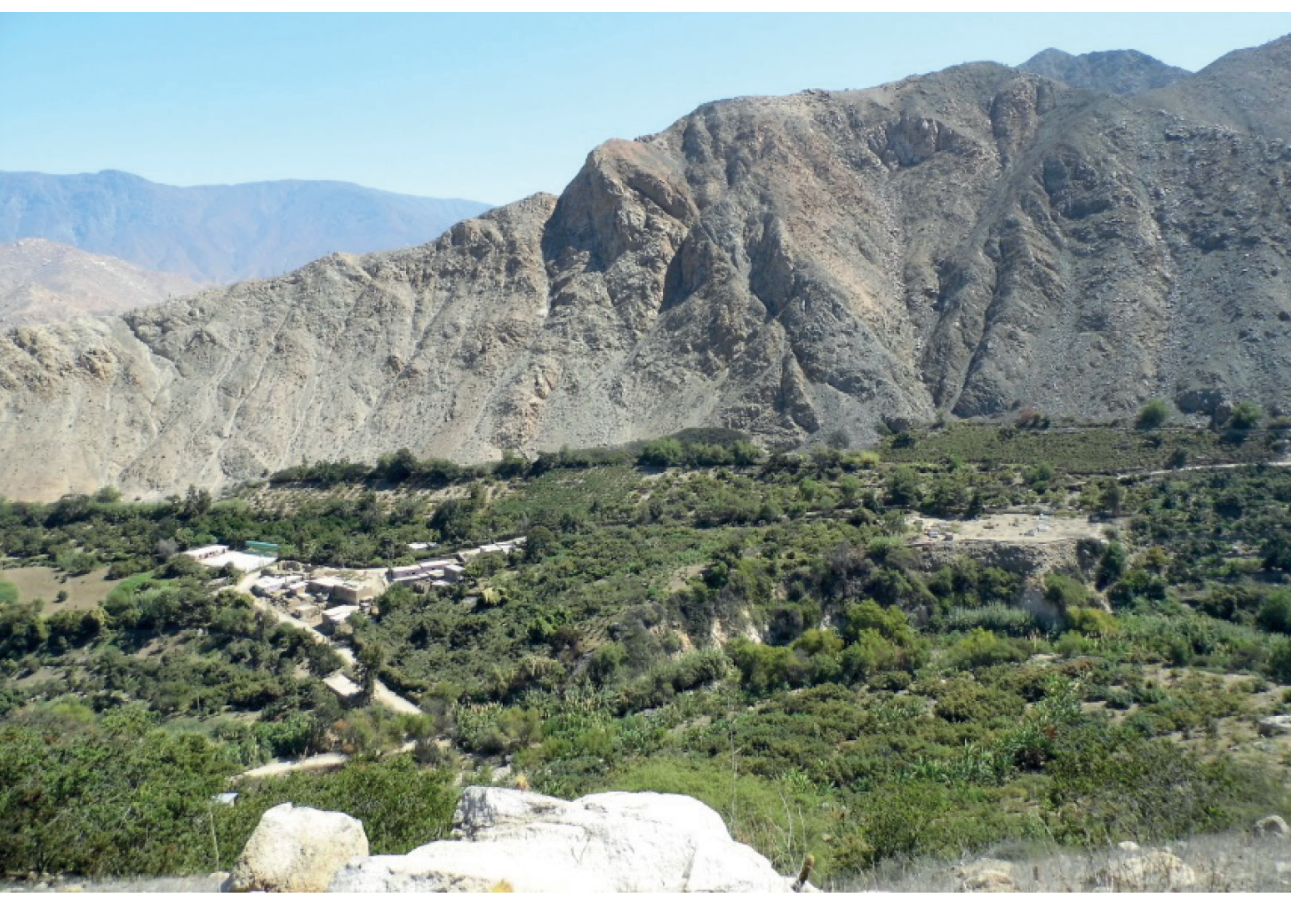

geopolítica de primer orden (Zubieta; 2003). El actual pueblo de Chasquitambo se ubica a 755 metros de altura sobre el nivel del mar, justo en el lugar donde el río Purísima (uno de los más grandes afluentes del río Fortaleza en el valle medio) se une al valle de Fortaleza por la margen izquierda. El cauce del río Purísima al ingresar al valle es encajonado y profundo, motivo por el cual no significa mucho riesgo para la población local en época de crecida. Por su clima cálido, los valles contiguos (del Fortaleza y del Purísima) son áreas propicias para el cultivo, principalmente de árboles frutales. El anexo de Colquioc, en cambio, se ubica en la margen izquierda del río Purísima, en la sección media de este valle, conformado por unas 20 viviendas dispersas, cuya población se dedica a la agricultura.

El río Fortaleza es un extenso río que se origina en las cercanías de la laguna Conococha (lagunas de Huamblac y Macato), tiene 111 kilómetros de largo, sirviendo de límite natural entre las provincias de Bolognesi (margen izquierda) y la provincia de Recuay (margen derecha); con curso sinuoso en la cuenca alta, hasta llegar a las inmediaciones del pueblo de Cajacay, donde se inicia el valle medio, pasando luego junto a los pueblos de Raquia y Chasquitambo, para desembocar al Océano Pacífico al norte del pueblo de Paramonga.
Figura 1. Vista panorámica del anexo de Colquioc. 
En el ámbito de todo el distrito de Colquioc hemos registrado más de 20 sitios arqueológicos, de los cuales en el presente trabajo presentamos solo los del anexo de Colquioc. Las prospecciones arqueológicas desarrolladas en esta área han sido sistemáticas, identificando previamente la existencia de algunos sitios arqueológicos mediante la revisión de fotos aéreas (SAN) y satelitales, realizando luego el barrido prospectivo de este sector del valle Purísima, a fin de registrar la totalidad de evidencias arqueológicas.

\section{Sitios arqueológicos del anexo de Colquioc}

El anexo de Colquioc (UTM 18L 0218650E, $8860939 \mathrm{~N})$ se encuentra ubicado en la margen derecha del río Purísima, frente a la confluencia de la quebrada Cochop y el río Purísima. Hacia el lado Sur y Sureste del anexo (entre las quebradas Cochop y Pescado) se han registrado una serie de sitios arqueológicos; desde un Complejo Arqueológico Monumental -donde se ha registrado evidencias arqueológicas e históricas (bienes arqueológicos mixtos) a lo largo de más de 20 hectáreas- hasta sitios con evidencias arqueológicas aisladas. La riqueza arqueológica entre el Cerro Pescado y dicho anexo es variada y diversa; sin embargo, por cuestiones de extensión, se presentará las más representativas.

\section{Complejo arqueológico monumental de Colquioc}

Se ubica en la margen izquierda del río Purísima, entre las confluencias de las quebradas Cochop y Pescado. Todo el complejo se emplaza entre áreas de terrazas aluviales y ciertas lomadas de cerros y colinas bajas. Su posición respecto del anexo de Colquioc es el lado suroeste, a menos de 550 metros en línea recta. La altitud sobre el nivel del mar varía entre los 1193 y 1260 metros. El entorno inmediato del sitio presenta abundantes plantas de tipo herbácea, cactáceas y gramíneas. De acuerdo a las evidencias arqueológicas muebles e inmuebles registrados, este complejo arqueológico presenta 3 zonas o sectores bien definidos. Una primera zona (sector I), ubicada al lado suroeste del complejo arqueológico, está conformado por el Pueblo Viejo de Colquioc. Una segunda zona (sector II), que rodea el primer sector, tanto por el lado sur, sureste y norte (siendo la parte intermedia entre el sector I y sector III), es un sector netamente funerario. La tercera zona identificada (sector III) está ubicado al extremo norte y noreste del sitio, caracterizado por presentar dos pirámides. Se podría considerar un cuarto sector (al lado este del sector III); pero, por la escasez de evidencias, se las considera como elementos arqueológicos aislados. Tomando en cuenta todos estos sectores, la extensión del complejo arqueológico supera las 20 hectáreas, donde hemos podido identificar evidencias arqueológicas prehispánicas y coloniales tempranas (siglo $\mathrm{XVI}$ ); en este sentido, este complejo tiene la categoría de un "bien arqueológico mixto".

Sector I: Pueblo Viejo de Colquioc. Este sector, ubicado al lado suroeste del complejo arqueológico, se emplaza sobre una terraza aluvial de ligera pendiente. Tanto por los lados norte, oeste y sur, limita con los terrenos agrícolas, los cuales se han habilitado sobre un talud de fuerte pendiente. Los lados noreste y sureste son terrenos eriazos (con evidencias funerarias, consideradas parte del sector II). Este sector se encuentra más cerca de la quebrada Pescado (en su margen derecha) y es por el lado de esta quebrada donde la actividad agrícola ha ido ganado terreno, sobre todo al pie de los cerros. La posición georreferenciada de este sector son las coordenadas UTM 18L 0218839E, 8860372N, a 1195 metros de altitud (punto tomado en la parte central de la plaza). El sitio arqueológico de Pueblo Viejo tiene un patrón ortogonal en damero (típico patrón español, de la época de las reducciones coloniales tempranas), con una plaza central cuadrada (de unos 40 metros por lado) y manzanas divididas por calles rectas (de unos 5 a 5.5 metros de ancho); orientado, ligeramente, de noroeste a sureste. La iglesia está ubicada al lado noroeste de la plaza, hacia sus otros lados se pueden apreciar las bases de los muros de otras construcciones; aunque en el lado oeste se tiene la apariencia de un espacio abierto sin construcciones (solo se aprecia las bases de muros que dan a la plaza, hacia el lado contrario se tiene un espacio totalmente libre, posiblemente se trate del cementerio del pueblo). Es probable que la cantidad de manzanas no superaban las 8 , a las que sumado la plaza se estaría formado un damero de 3 x 3; los únicos espacios para ampliar el damero son los lados este y oeste (espacios donde futuras investigaciones podrán determinar la verdadera 

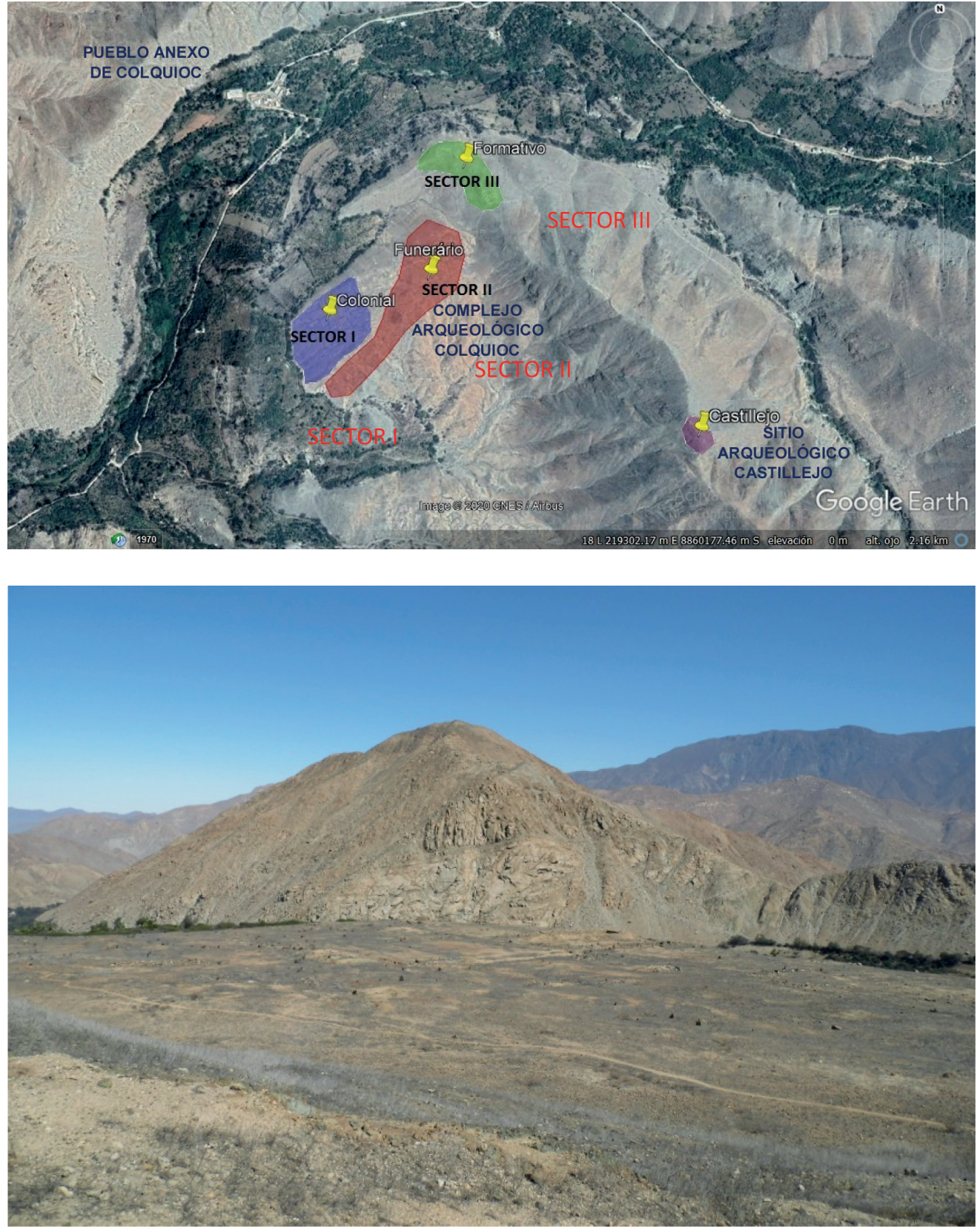

Figura 2:

Panorama de

la ubicación en

vista satelital

(Google Earth) de

los tres sectores

del complejo

arqueológico

Colquioc y del

sitio arqueológico

Castillejo.
Figura 3:

Vista panorámica del Pueblo Viejo de Colquioc. extensión del núcleo urbano), ya que, tanto al norte, como al sur, se observan taludes por lo que las laderas se van haciendo más pronunciadas. En este punto es preciso seńalar que, al lado sur de toda el área urbana, casi al límite, se observa un probable muro perimétrico. Lo señalamos como un posible muro debido a que no se han identificado cabeceras de muro, propiamente dicho; solo se ha observado acumulación de abundantes piedras de diversos tamaños (como si fueran cascajos) en una hilera de más de 150 metros de largo, orientado de noreste a suroeste (coordena- da referencial en el punto medio: 18L 0218828E y $8860259 \mathrm{~N})$. A lo largo de esta hilera hay bloques de piedras grandes alineadas en dos filas, haciendo un ancho aproximado de 1.20 metros, colocados en algunos casos de forma vertical y careado. Hacia el lado sur de este posible muro hemos identificado algunos alineamientos de piedras formando espacios circulares, en otros casos sólo pequeñas hondonadas circulares, que claramente contrasta con la superficie del suelo (posibles estructuras funerarias subterráneas). 
La estructura rectangular más sobresaliente es la iglesia del Pueblo Viejo de Colquioc, ubicada al lado norte de la plaza, de 21 metros de largo por 8.40 metros de ancho, tiene una orientación ligera de noroeste a sureste. El único acceso está al lado sureste de la estructura, con 2.15 metros de ancho. Los muros tienen un ancho de 0.65 metros, la altura máxima conservada es de 1.90 metros. Fue construido con adobe y mortero de barro, como se aprecia en los muros largos laterales; aunque la pared donde se ubica el vano de acceso fue construida con piedras canteadas y mortero de barro, la cimentación de la estructura también presenta estas características constructivas. La posición georreferenciada de esta construcción son las coordenadas UTM 18L 0218823E y $8860404 \mathrm{~N}$. La estructura rectangular de la iglesia se encuentra

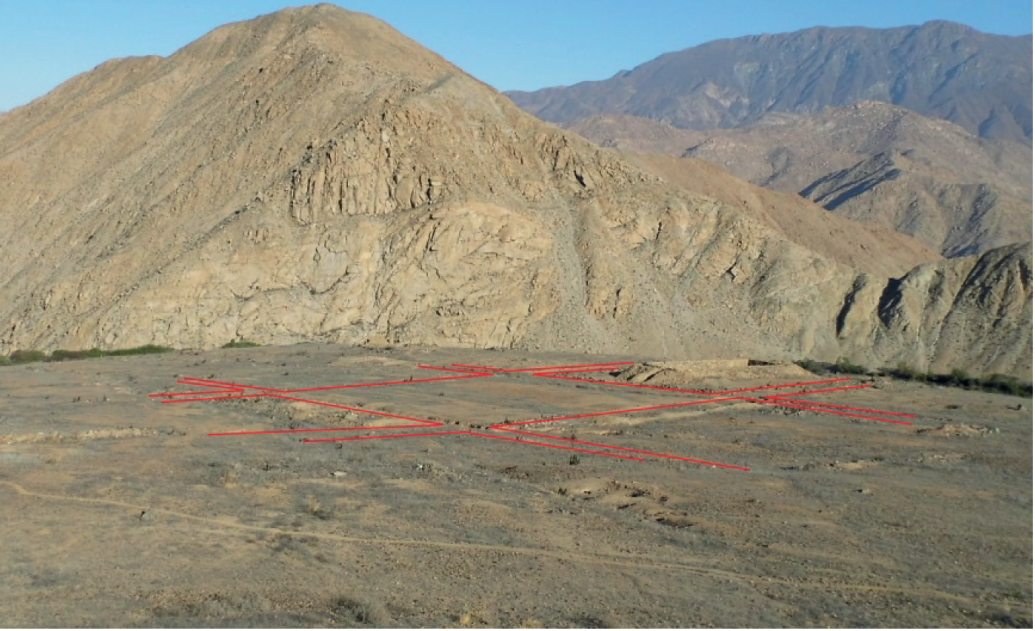

Figura 4. Vista del patrón ortogonal del Pueblo Viejo de Colquioc.

en la parte central de toda la manzana, en los límites de la manzana se construyeron muros perimétricos que daban hacia la calle (posiblemente de baja altura, ya que hay evidencias de poca densidad del material constructivo), no fue posible definir el ancho de los muros perimétricos, debido a su pésimo estado de conservación.

El estado de conservación de esta iglesia es pésimo (aproximadamente 98\% de destrucción), la edificación se había habilitado para la construcción de un reservorio moderno, aprovechando las dimensiones y las paredes de la construcción. Los muros originales de la iglesia sólo se conservan en menos del 5\%, gran parte de las paredes fueron reconstruidas con los mismos materiales de la iglesia (piedras y adobes sueltos y superpuestos) para el reservorio. El espacio interno fue totalmente limpiado, los escombros culturales que cubrían parte de este espacio fueron retirados hacia los lados laterales de los muros. El vano de acceso fue sellado con piedras y adobes superpuestos. En dirección oeste de la estructura se abrió una pequeña canalización para colocar tuberías que conectará con este reservorio. La intención de habilitar el reservorio no fue concluida. Los materiales asociados a la iglesia fueron, principalmente, restos óseos (de humano y animales pequeños); en el lado del ingreso se ha identificado pequeños hoyos de huaqueo. De acuerdo a la manifestación de un poblador, de la parte interna de esta construcción (iglesia), durante el tiempo de la modificación para el reservorio, se extrajeron varios fardos funerarios; testimonio que podría confirmarse por la presencia de restos óseos y fragmentos de cerámica en el espacio interno de la iglesia.

En las manzanas ubicadas al este y sur de la plaza se ha identificado estructuras rectangulares en cada una de ellas, ubicadas en el lado de la fachada que da a la plaza. La estructura de la manzana oriental tiene 25 metros de largo por 7.50 metros de ancho, dividido en tres espacios internos: dos cuadrangulares laterales y una rectangular en la parte central. La estructura de la manzana meridional tiene 26 metros de largo por 8 metros de ancho, también, dividido en tres espacios. Las técnicas constructivas se caracterizan por sus paredes con adobes unidos con mortero de barro, cimientos de piedras canteadas unidas con mortero de barro. Hay otras estructuras a los lados laterales de estas estructuras, construidas con muros de piedras canteadas y mortero de barro.

En dirección sur de la plaza, a unos 50 metros, hay un muro de piedras canteadas unidas con argamasa (UTM 18L 0218880E, 8860329N), de unos 0.64 metros de alto y 14 metros de largo. Este muro posiblemente sea la esquina de una manzana adicional. En el extremo oeste del Pueblo Viejo (UTM 0218732E, 8860324N, a 1196 metros de altitud), al límite de donde termina el terreno de ligera pendiente e inicia el talud (terreno agrícola), hay un espacio donde se ha registrado un batán de 0.67 metros de ancho por 0.75 metros de largo y un alto de 0.43 metros; sobre el batán hay fragmentos 
de manos de moler. Asociado a este batán hay un pequeño montículo, posiblemente una construcción. Se aprecia en los alrededores abundante fragmentos de cerámica.

A unos 35 metros al norte del batán hay una estructura construida con muros de tapial, emplazada sobre una terraza sostenida por un muro de contención de 0.60 metros de alto. Los cimientos de la estructura fue construido con piedras canteadas y mortero de barro, la altura máxima conservada de los muros es de 2.40 metros, y el ancho del muro llega a 0.55 metros; esta estructura tiene 6 metros de largo por 6 metros de ancho (planta cuadrangular); sin embargo, en la parte interna tiene dos ambientes de planta rectangular, el más grande tiene 4.60 metros de ancho con 6 metros de largo, siendo el espacio pequeño un patio pequeño de 1.40 metros de ancho en la parte contigua a la fachada. El vano de acceso hacia esta estructura es de 1.40 metros de ancho. Adosado a esta estructura de tapial hay dos estructuras más pequeñas y contiguas (lado norte de la estructura), una con muros de adobes de 3.50 metros de largo por 3.10 metros de ancho; la otra, más pequeña, construida con piedras canteadas y mortero de barro, tiene 2.10 metros de largo por 1.50 metros de ancho. En dirección noreste se han registrado otras estructuras; una de 7 metros de largo por 6 metros de ancho, el muro mejor conservado es de 0.60 metros de alto, edificado mediante pircado de piedras canteadas con mortero de barro (presenta la misma planta constructiva que la estructura con muros de tapial). Otra estructura adicional de 4 metros de largo por 3.20 metros de ancho, edificado a base de piedras canteadas unidas con argamasa, muy destruido.

En determinado espacio de este sector hemos identificado 4 petroglifos o quilcas de distintas características. Ubicado al lado este del sector (en las coordenadas UTM 18L 0218941E - 8860410N), se identificó un afloramiento rocoso con motivos de círculos, espirales y líneas gruesas con motivos zoomorfos. Una segunda roca de 1.87 metros de largo por 0.65 metros de alto, ubicada a 20 metros al sur del primero (coordenadas UTM 18L 0218937E $8860390 \mathrm{~N})$. En este último hemos identificado un ave en bajo relieve, y motivos geométricos, así como círculos concéntricos. Un tercer petroglifo (coordenadas UTM 18L 0218814E - 8860372N) se encuentra en la esquina noreste de la plaza, presenta motivos

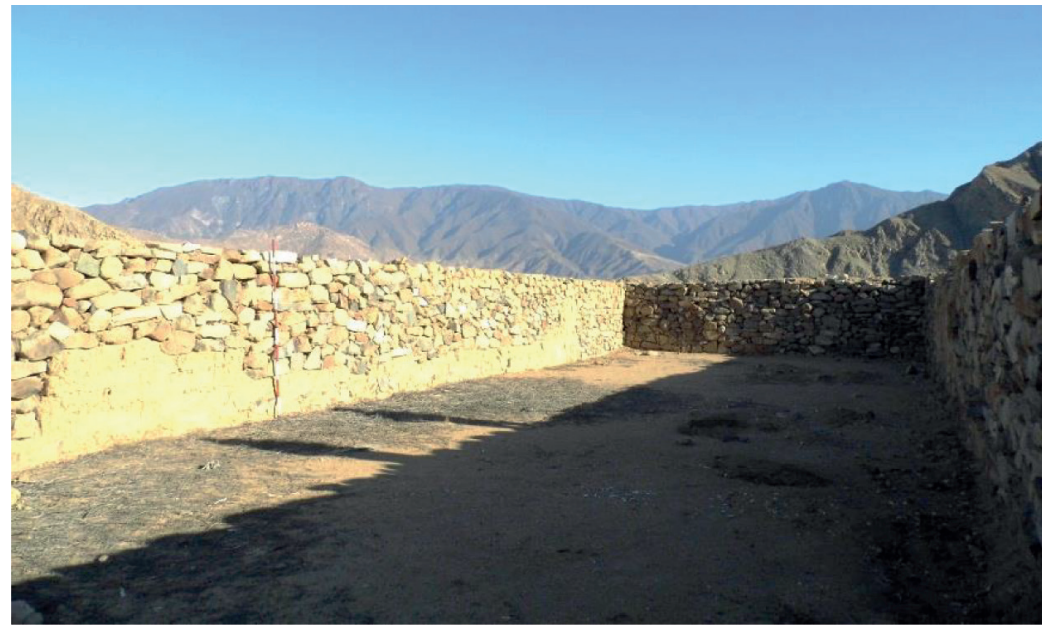

Figura 5: Vista de la parte interna de la Iglesia del Pueblo Viejo de Colquioc, nótese los adobes originales y las piedras levantadas en época moderna para habilitar un reservorio.

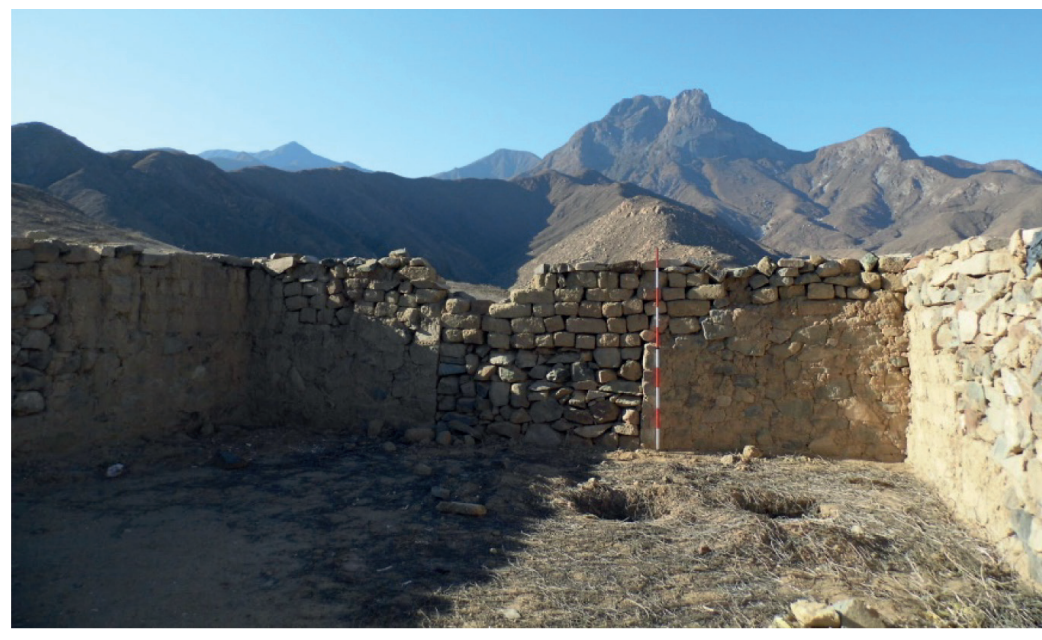

Figura 6: Vista del acceso a la Iglesia del Pueblo Viejo de Colquioc.

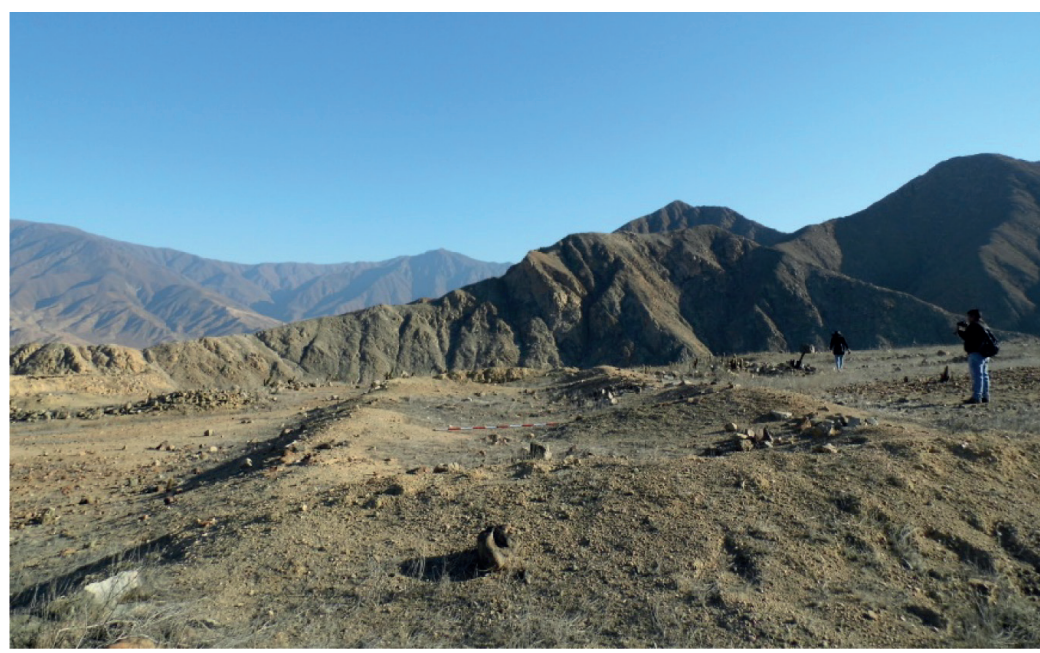

Figura 7: Vista de estructura rectangular al este de la plaza del Pueblo Viejo de Colquioc. 


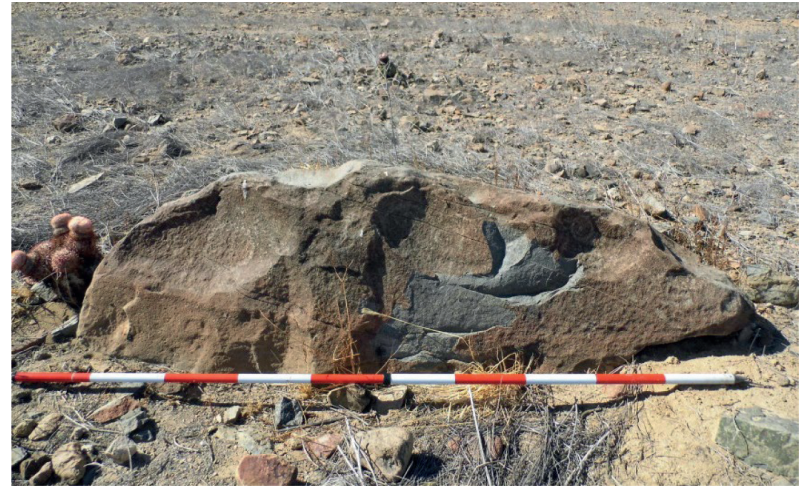

Figura 8: Vista de petroglifo 1 del complejo arqueológico Colquioc.

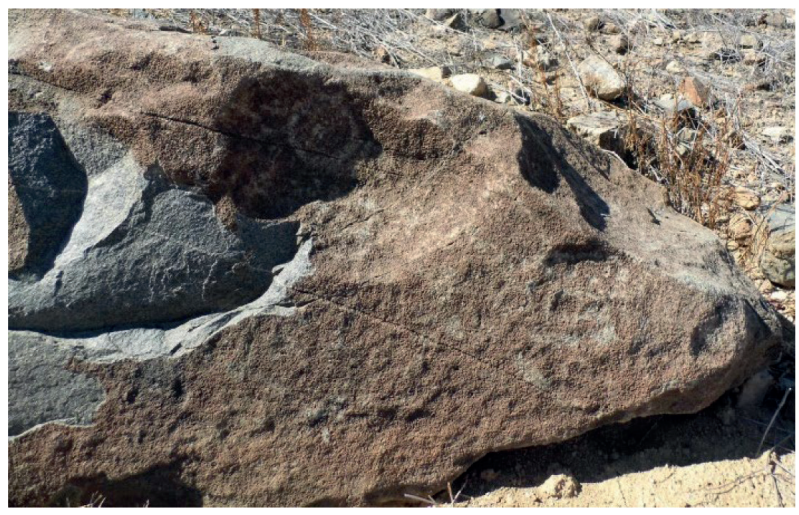

Figura 9: Vista en detalle de petroglifo 1.

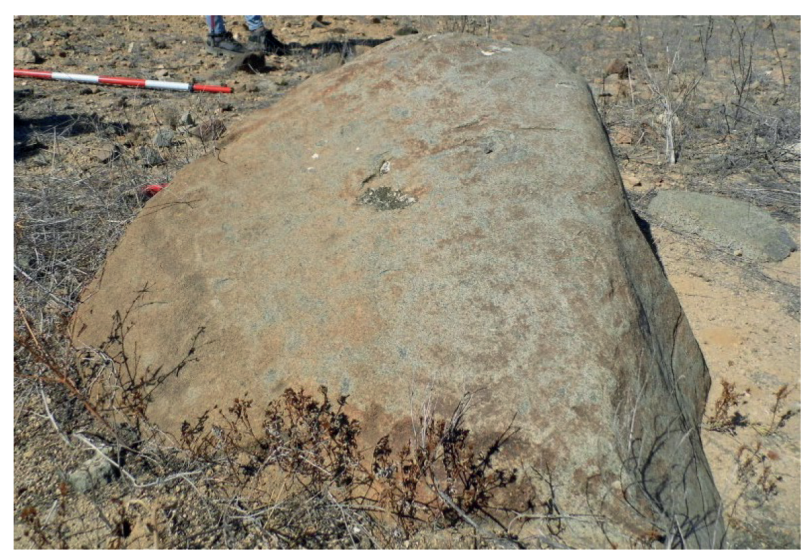

Figura 10: Vista en detalle de petroglifo 2.

geométricos. El último petroglifo (el cuarto) se encuentra al lado suroeste del área urbana (coordenada UTM 18L 0218802E - 8860317N), donde el motivo representado en bajo relieve es el de una "X".

Sector II: Área Funeraria. Este sector se caracteriza por la presencia de estructuras funerarias circulares subterráneas tipo cista, estas se han emplazado sobre promontorios naturales de poca altura. El total de colinas (subsectores) con evidencias de estructuras funerarias es de cinco, en las siguientes coordenadas UTM 18L: a) $0219002 \mathrm{E}, 8860347 \mathrm{~N}$, a 1236 metros. b) $0219039 \mathrm{E}, 8860414 \mathrm{~N}$, a 1240 metros. c) $0219051 \mathrm{E}, 8860461 \mathrm{~N}, 1214$ metros. d) $0219075 \mathrm{E}$, $8860572 \mathrm{~N}, 1230$ metros. e) $0219191 \mathrm{E}, 8860661 \mathrm{~N}$, a 1235 metros de altitud.

Las estructuras circulares varían entre 0.67 y 1.20 metros de diámetro, muchas de estas huaqueadas, permiten visualizar muros de piedras canteadas. Estas estructuras se han emplazado sobre terrazas artificiales, donde la cima natural de la colina fue cortada. En ciertos espacios de la terraza artificial se han identificado hondonadas circulares, que contrastan con el suelo de la terraza, lo que indicarían posibles estructuras funerarias intactas. Producto del huaqueo, algunas de las estructuras funerarias han sido destruidas y disturbadas. Además de fragmentos de cerámica y restos óseos, también hemos identificado en superficie pequeñas placas de cobre. En las coordenadas $18 \mathrm{~L}$ $0219075 \mathrm{E}-8860572 \mathrm{~N}$ se observó una estructura circular de 4.50 metros de diámetro, construido con piedras canteadas; el acceso orientado al noreste tiene 0.80 metros de ancho. Hacia el lado norte de esta estructura hay un camino de herradura de entre 0.60 y 0.85 metros de ancho.

Sector III: Pirámides del periodo Formativo. Este sector se encuentra ubicado en la margen izquierda del río Purísima, cerca de la confluencia de la quebrada Cochop con el valle, hacia el lado noroeste del Pueblo Viejo de Colquioc. El sector se encuentra emplazado sobre la cima de una colina, al pie de una cadena de cerros, que en su ascenso a las partes altas se dirige al Cerro Pescado (ubicado al sur de este sitio). $\mathrm{Su}$ posición georreferenciada son las coordenadas UTM 18L 0219161E - 8860749N, a 1240 metros de altitud.

Cabe señalar, en este punto, que, a nuestra llegada al sitio, este presentaba los hitos colocados por el Ministerio de Cultura (que por cierto muchos de ellos se habían movido de su lugar de colocación) que delimita la zona arqueológica. Los componentes arquitectónicos de este sector son los siguientes:

Conjunto Piramidal 1: Este sector presenta dos estructuras piramidales, la primera en forma de "L", conformado por un cuerpo central (montículo piramidal) de 65 metros de largo (noreste-suroeste) por 


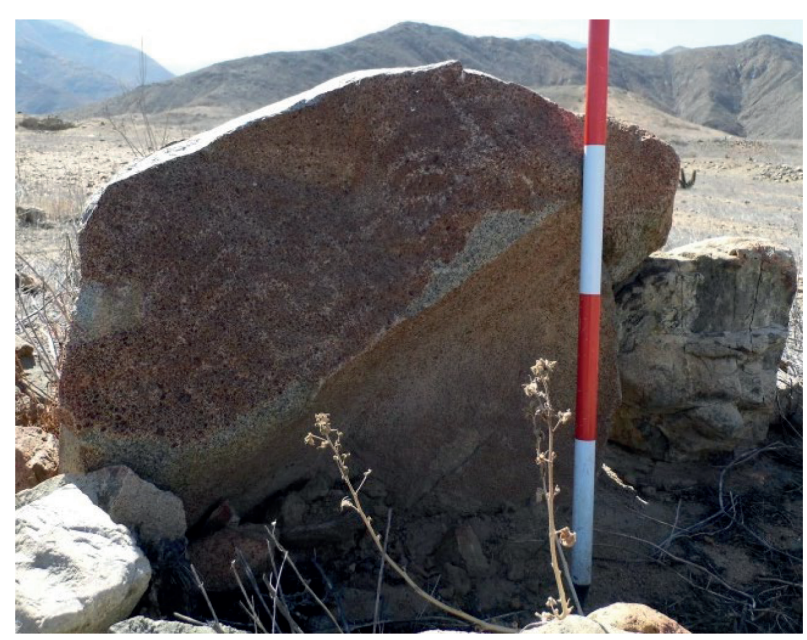

Figura 11: Vista en detalle de petroglifo 3.

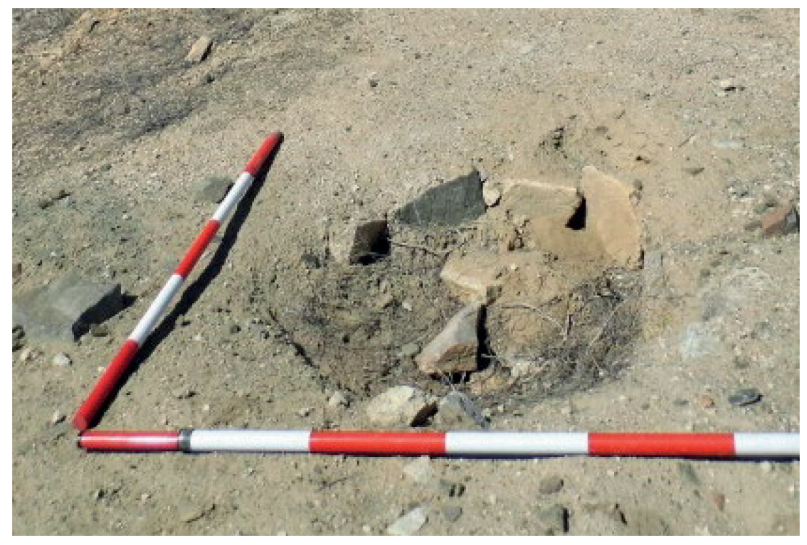

Figura 12: cista funeraria disturbada del sector II.

24 metros de ancho (noroeste-sureste) y 2.20 metros de alto; articulado a un brazo de menor tamaño ubicado al lado este, de 25 metros de largo (noroestesureste) por 15 metros de ancho (noreste-suroeste) y 1.80 metros de alto. En la parte central de entre ambos montículos, a unos 30 metros del único brazo existente, y a unos 20 metros al sureste del montículo central, se observa una estructura circular a modo de plaza circular hundida de 8 metros de diámetro. El muro que circunda la plaza circular se encuentra casi en su totalidad destruido, conservándose en una parte sólo unos 0.40 metros de altura.

El cuerpo central de esta construcción que tiene forma de "L", en la cima de su extremo oeste, se han identificado cabeceras de muros que se proyectan en sentido noroeste-sureste. Siguiendo hacia la parte más alta y central, los niveles que se superponen a esta estructura central no son claros; sin embargo, podemos identificar muros de contención, llegándose a contar un total de 3 niveles constructivos, para los cuales a su vez se estaría aprovechando la altura natural del terreno (por la presencia de los afloramientos rocosos), desde donde se construyen estos muros. En la parte más alta hemos identificado la acumulación y dispersión de piedras canteadas de regular tamaño, estos habrían formado parte de las estructuras que se habrían construido sobre esta estructura piramidal, pero que no se aprecia con claridad las características de estas. La confusión de las formas de las estructuras se debe a que el huaqueo intensivo en el sitio han generado hoyos de apariencia circular, donde los muros de hasta 0.30 metros de alto saltan a la vista; sin embargo, las cabeceras de muros que se observan en la superficie son rectas y aparentemente no encierran un espacio que podamos identificar como cuadrangular o rectangular. En el brazo oriental de la estructura piramidal sólo se ha podido apreciar un alineamiento de muro que va en sentido noroeste - sureste; y al igual que en todo el sitio, con abundantes fragmentos de cerámica de carácter doméstico.

Para ser más precisos en cuanto a la ubicación georeferenciada de esta primera estructura piramidal articulada en forma de "L", se toma como referencia la estructura circular que esta al pie sureste del cuerpo central. Sus coordenadas UTM son: 18L 0219131.19 E - 8860763.36 N.

Estructuras Asociadas: bajando por la cresta que continúa en sentido suroeste, desde la parte alta de la estructura piramidal en forma de "L" (a unos 115 metros), se han identificado estructuras circulares subterráneas a manera de "cistas funerarias", con muros edificados con piedras canteadas (según se ve en las cistas expuestas producto del huaqueo). El diámetro de estas cistas es de aproximadamente 0.90 metros. En un caso se identificó al interior de una estructura cuadrangular de unos 4.20 metros por lado. Entre los materiales superficiales asociados a esta estructura se aprecian: fragmentos de cerámica, y restos óseos pequeños. Las coordenadas UTM de esta estructura es 18L 0219014E - 8860719N.

En dirección sureste, respecto de la plaza circular, a unos 30 metros se ha identificado un montículo de planta rectangular, con algunas cabeceras de muro visibles. El acceso estaría ubicado al lado noroeste. Las coordenadas UTM de esta estructura es: 18L $0219161 \mathrm{E}-8860749 \mathrm{~N}$. 


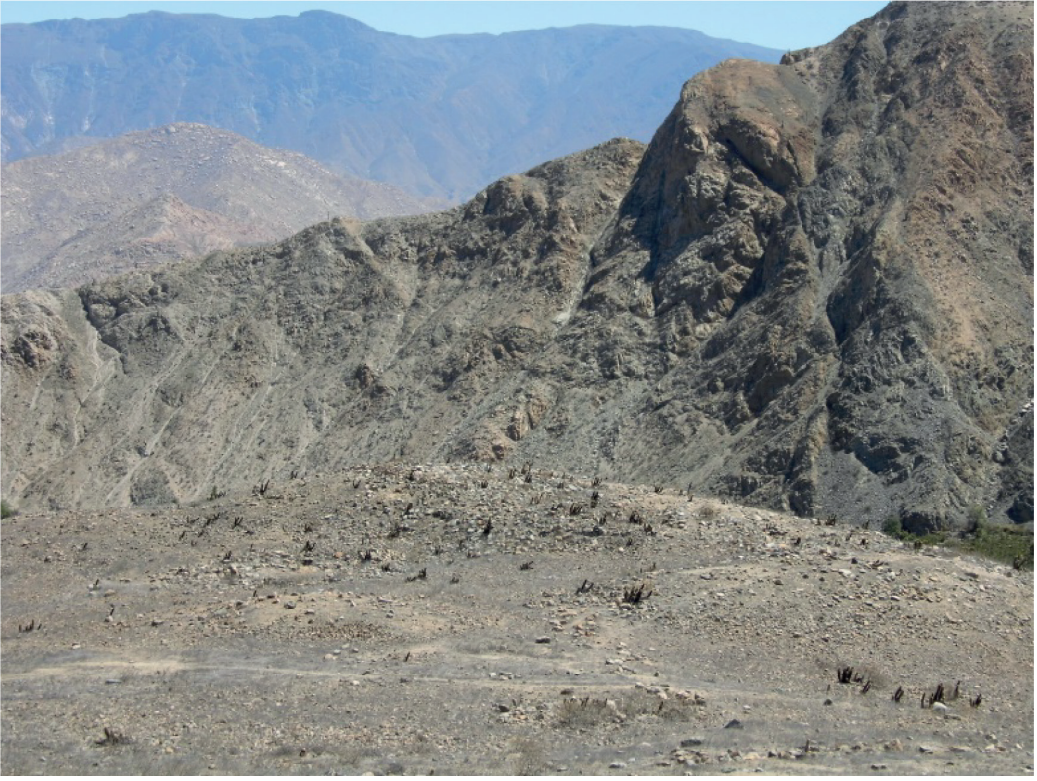

Figura 13: vista panorámica del conjunto arquitectónico piramidal 1.

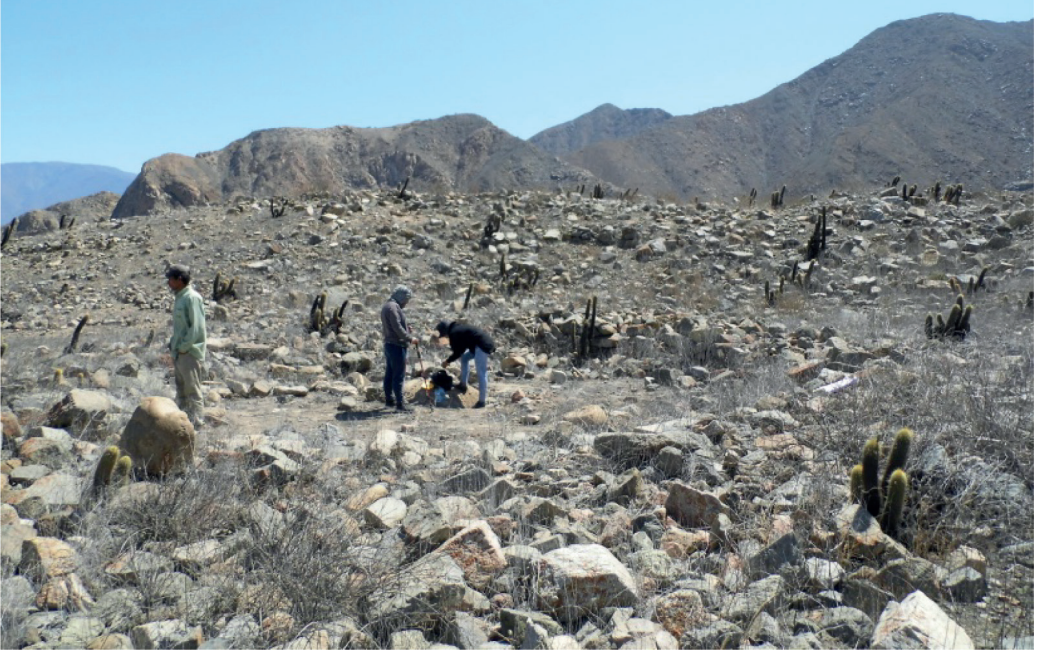

Figura 14: vista panorámica de la plaza circular hundida.

Estructura Piramidal 2. Esta estructura se encuentra ubicado al lado sureste de la primera, en las coordenadas UTM 18L 0219230E - 8860701N. La altura de esta pirámide está en función a la elevación del terreno natural, debido a que esta se ha construido sobre una ladera poco pronunciada, en el extremo norte de toda la colina del Cerro Castillejo (no tenemos una referencia exacta sobre el nombre de estos cerros, pero los pobladores llaman a todo este lugar como Castillejo, desde la parte más baja hasta la par- te más alta, al pie del Cerro Pescado). Al pie de esta estructura piramidal hay un espacio de planta irregular de 18 y 12.70 metros de diámetro (por cada eje), no se aprecia los muros propiamente dicho, sólo la acumulación de piedras canteadas que rodean el espacio circular, producto del colapso de los muros. Por la densidad de piedras expuestas en la superficie y por las características que se pueden apreciar (piedras sueltas), es probable que esta estructura sea un corral de construcción reciente (no arqueológico).

La estructura piramidal presenta 3 niveles o plataformas escalonadas bien marcadas, orientado en un solo eje de inclinación de noroeste-sureste. El acceso no es definido, pero podría ser por el lado extremo noroeste. La primera plataforma, desde el pie de la estructura hasta la parte más alta tiene 8 metros de altura, tiene una forma de media luna; este primer nivel presenta un espacio circular hundido de unos 19.20 metros de diámetro, con cabecera de muro de 0.65 metros de ancho, si bien no se ha podido identificar muros conservados, las piedras canteadas densamente acumuladas y dispersas nos da una idea de que haya existido; la hondonada que se puede que ver sobrepasa el 1.50 metros de profundidad. Dentro de esta plataforma circular hundida se identificaron estructuras circulares más pequeñas, posiblemente cistas con muros, la primera de 0.40 metros de ancho y de 0.85 metros de diámetro; y la segunda de 0.20 metros de diámetro con muros de 0.55 metros de ancho. La técnica constructiva de estas cistas es de aparejo rustico, elaborados con piedras canteadas unidas con mortero de barro.

Desde la primera plataforma, el acceso hacia la segunda plataforma de la pirámide se estaría realizando por una pequeña escalinata central, con orientación al eje de la pirámide. Aquí se observa un pequeño talud de ligera pendiente, donde se ha registrado un muro de contención de 0.60 metros de alto conservado. No se puede apreciar la dimensión completa de los muros de contención debido a que estos se encuentran totalmente cubiertos por el derrumbe. La vista de la escalinata no es tan clara, pero esta nos estaría llevando a una plataforma de forma rectangular, donde se habrían construido algunas estructuras que no están bien definidas por el mal estado de conservación, aunque se aprecian ciertos alineamientos de muros muy destruidos. Esta segunda plataforma tiene 6 metros de alto y 5 metros de ancho. 


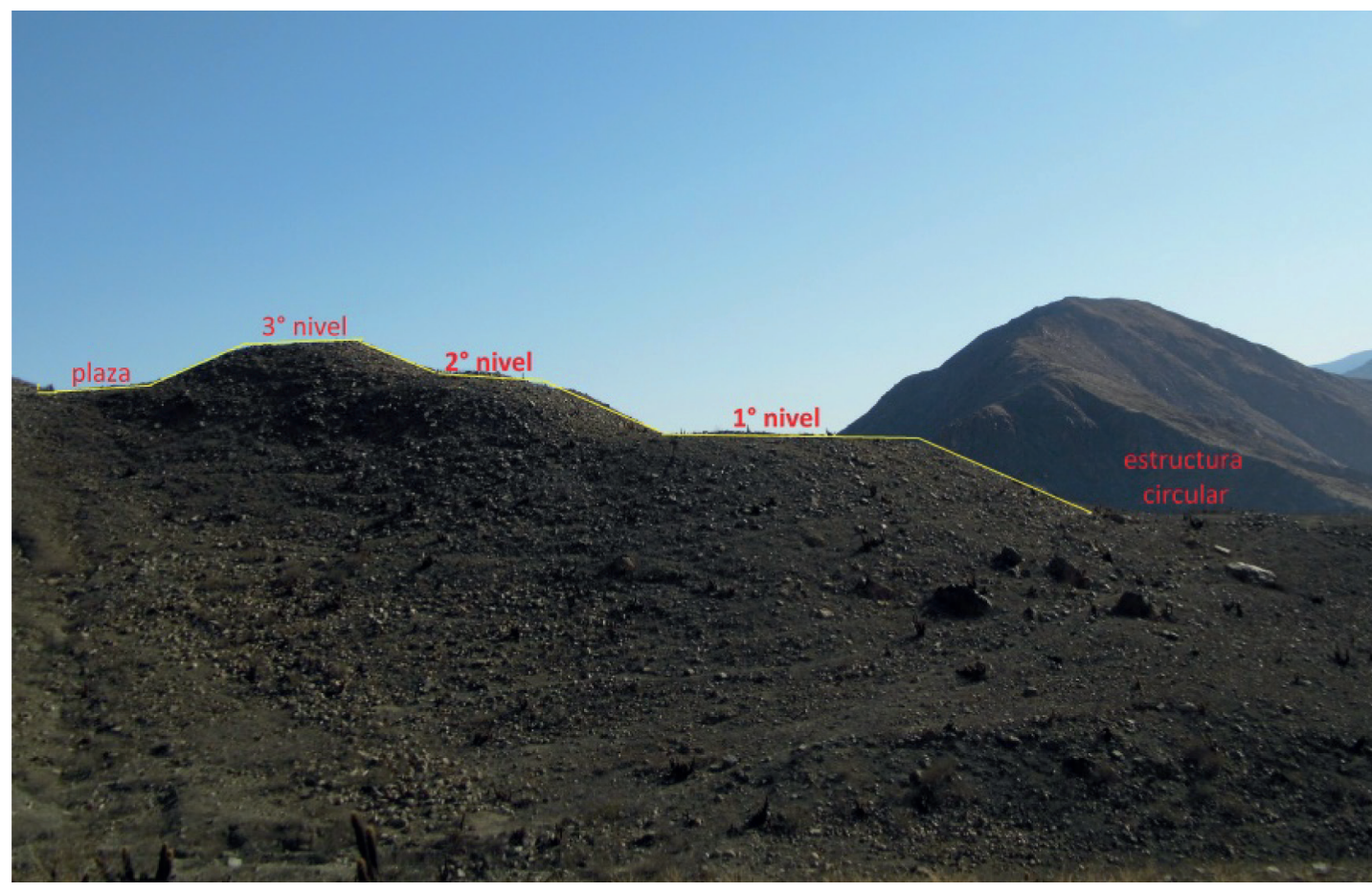

Figura 15.

Vista

panorámica

del conjunto

arquitectónico

piramidal 2.

En la parte más alta, se encuentra el tercer nivel o plataforma, de 3 a 4 metros de ancho y 3 metros de alto desde la segunda plataforma, a la que se accede por un pequeño talud desde la segunda plataforma. No se ha identificado elementos estructurales (sea escalinata o muros de contención) para acceder a este último nivel, donde claramente podemos apreciar una plataforma rectangular en la parte superior. Parte de esta plataforma presenta hoyos profundos de huaqueo, donde hay materiales óseo humanos, restos de quema y fragmentos de cerámica, que se han expuesto a la intemperie. En la parte superior de este nivel se observa un hoyo profundo huaqueado, donde podemos observar el relleno constructivo de la pirámide; así como una cámara subterránea en la parte más honda de este huaqueo. Esta cámara subterránea se ha construido con lajas rectangulares y alargadas de piedras canteadas, a esta le cubre un relleno de piedras angulosas y barro hasta la superficie de este nivel.

Junto a este último nivel y al lado sureste, se tiene un espacio rectangular (patio o plaza pequeña) por debajo del nivel superior de la pirámide (más de 2 metros por debajo de la última plataforma). Esta tiene un aproximado de 20 metros de largo por 8 metros de ancho, presentando muros de contención que soportan el talud del cerro del lado sureste. Estos muros de contención no son visibles debido al derrum- be, se deduce su existencia por el huaqueo realizado en un lado de los extremos sureste de este espacio rectangular, donde se supone que limita con la ladera natural del cerro.

Elementos arqueológicos aislados: Hacia el este de las pirámides, cruzando una pequeńa quebrada, se ha registrado un alineamiento de piedras formando un espacio circular de 15 metros de diámetro. Adosado al muro interno de este espacio circular (lado noroeste) se tiene otra estructura de forma rectangular más pequeña, construida con muros a doble hilera de 0.55 metros de ancho. La dimensión exacta de estas no se puede determinar debido a la acumulación desordenada de piedras canteadas sobre estas. En la parte central de la estructura se evidencia una estructura disturbada más pequeńa, de tipo "cista" bajo la superficie. Las coordenadas UTM de esta estructura es: 18L 0219381E, 8860723N.

Bajando en dirección noroeste por la pequeña cima, en las coordenadas UTM 18L 0219258E $8860807 \mathrm{~N}$, se han identificado muros de contención aislados de unos 0.40 metros de alto; en la parte final de este muro hay una estructura circular de unos 2.50 metros de diámetro (de carácter funerario). Además de estas evidencias, se han identificado fragmentos de cerámica aislados o asociados a las estructuras descritas, de naturaleza doméstica. 


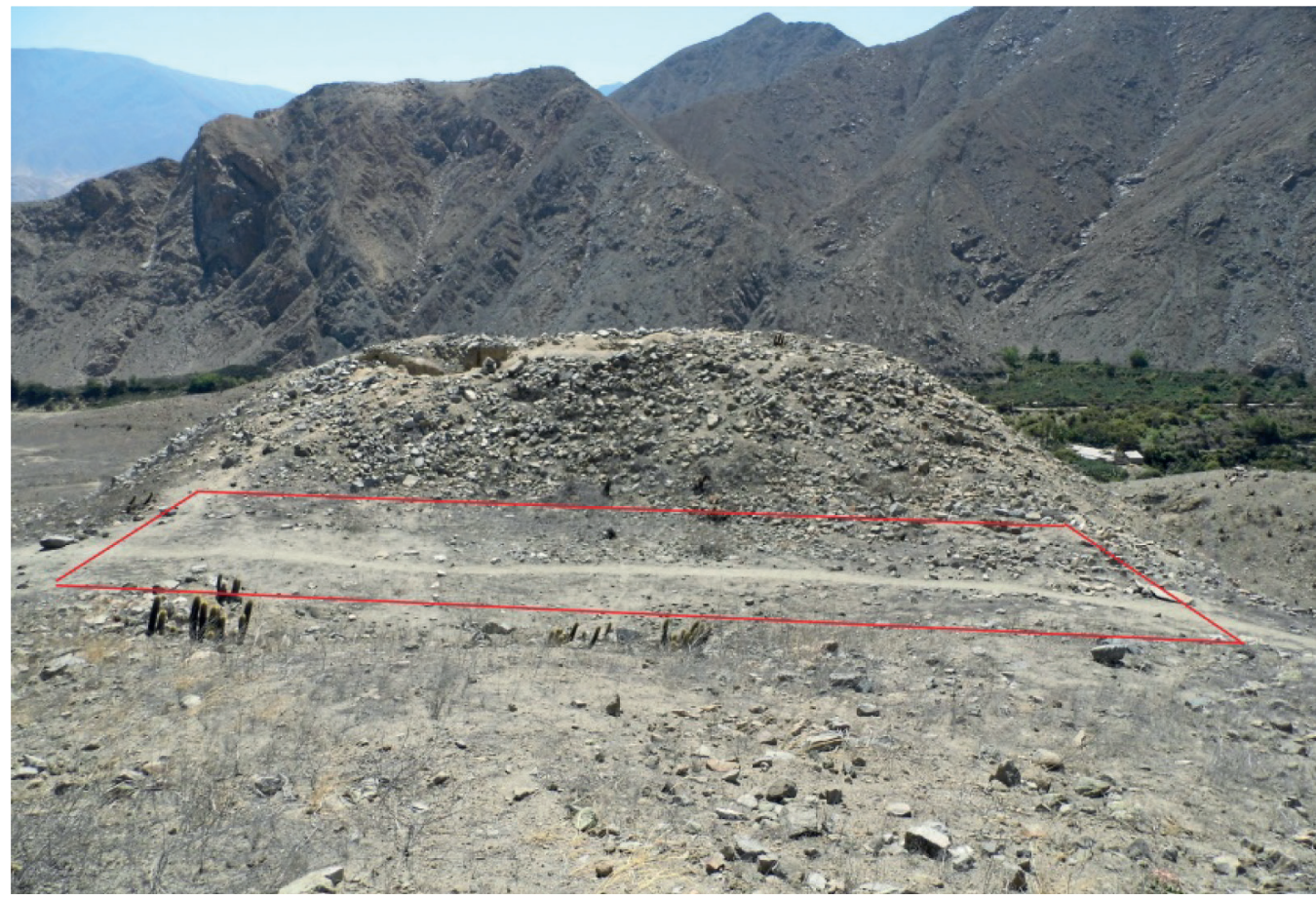

Figura 16.

Vista

panorámica

del patio 0

plaza superior

del conjunto

arquitectónico

piramidal 2.

\section{Sitio arqueológico Castillejo (Fortaleza Punta)}

Este sitio arqueológico se encuentra ubicado al lado sureste, a unos 800 metros respecto del complejo arqueológico monumental de Colquioc; en la margen izquierda de la quebrada Cochop, sobre la cima baja del espolón del Cerro Castillejo, que se proyecta desde el pie del cerro Pescado hasta el río Purísima. Este sitio está posicionado en las coordenadas UTM 18L 0219747E, 8860045N, a 1417 metros de altitud. Su emplazamiento se encuentra en una zona bastante accidentada, tanto el lado este como el oeste presentan fuertes pendientes, sólo la cima noroeste (accediendo desde la parte baja del valle por la cresta del espolón) es accesible hacia este sitio. El terreno es una zona escarpada, con presencia de plantas arbustivas, herbáceas y cactáceas.

El sitio Castillejo presenta dos plataformas contenidas por muros grandes a manera de murallas, que rodean tanto los lados este, oeste y sureste de la cima. La orientación de todo el sitio fortificado es ligeramente inclinada en sentido noroeste-sureste, siendo el lado noroeste por donde fácilmente se puede acceder; es probable que este espacio, además de entrada, haya sido el único para salir. Sin embargo, hay un camino moderno (con escalinata) construido por los pobladores para poder acceder por el lado sureste del sitio, subiendo por la falda este de la quebrada Cochop, aprovechando el derrumbe de la muralla en esta parte del sitio (es probable que el camino se haya construido para facilitar la visita turística del sitio). El primer amurallamiento fue construido con grandes piedras canteadas (de formas casi regulares), con presencia de pachillas entre piedras. El muro mejor conservado llega a tener 4 metros de altura, tiene 1.40 metros de ancho, de doble hilera con cascajo y mortero en la parte intermedia del muro; todo el amurallamiento tiene una forma elíptica (con orientación noroeste-sureste), o al menos es lo que se puede deducir a partir de la esquina curva del muro. Este primer amurallamiento estaría sosteniendo la primera plataforma, el lado oeste de esta se encuentra cubierta por el derrumbe del amurallamiento superior. Tanto en la esquina sur como la esquina sureste y el lado este de la plataforma se observan estructuras rectangulares, cuadrangulares y circulares, en algunos casos adosados a la cara interna de la primera muralla (la cual cumple función de muro de contención hasta la mitad de su altura y luego cumple función defensiva). Para ser más precisos, la mayoría de estas estructuras se encuentran adosadas a la cara interna de la muralla y están dispuestas de manera adjunta y continua. La visualización de los hoyos de huaqueo de algunas de estas estructuras nos ha permitido observar 


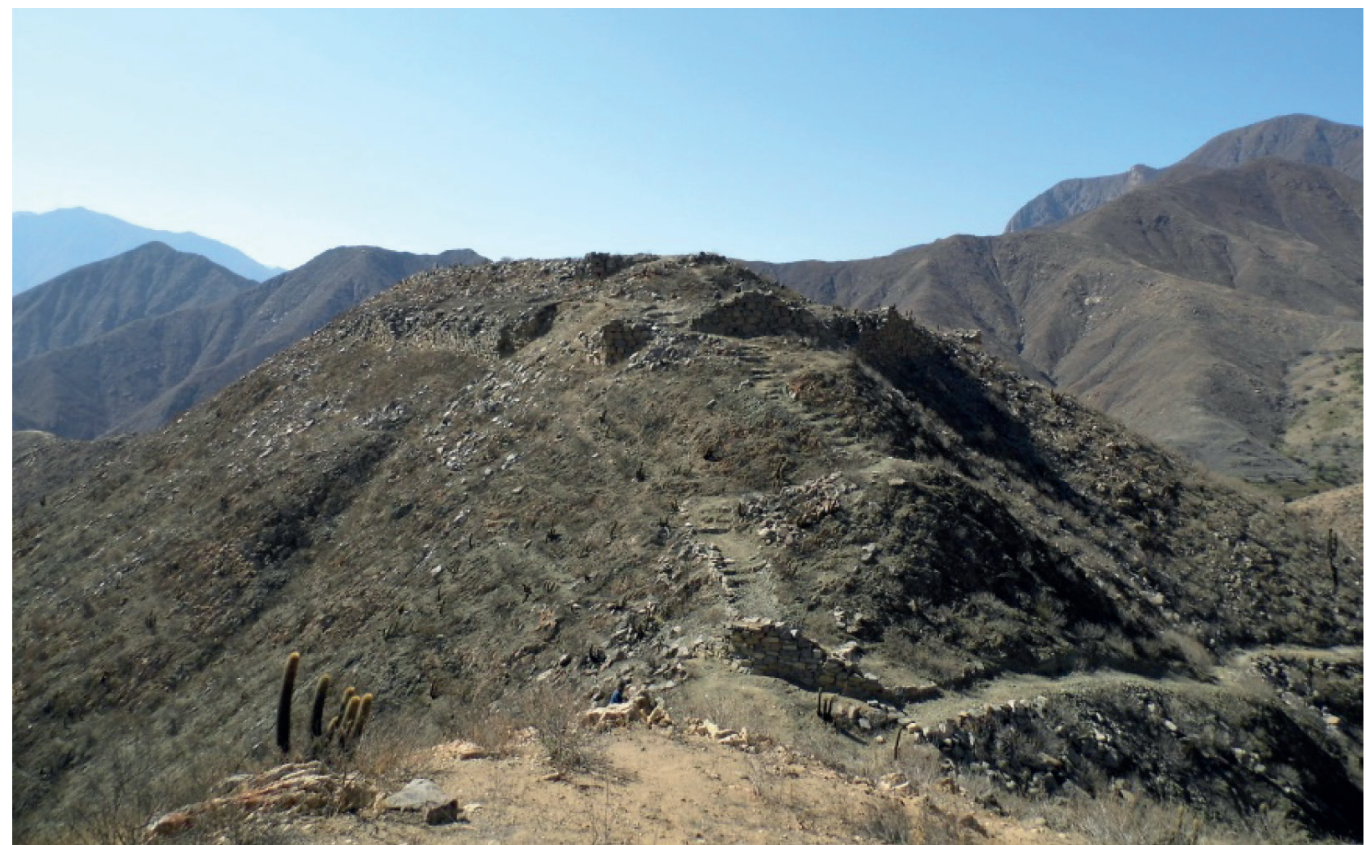

Figura 17

Vista panorámica del sitio arqueológico Castillejo, tomado desde el lado sur.

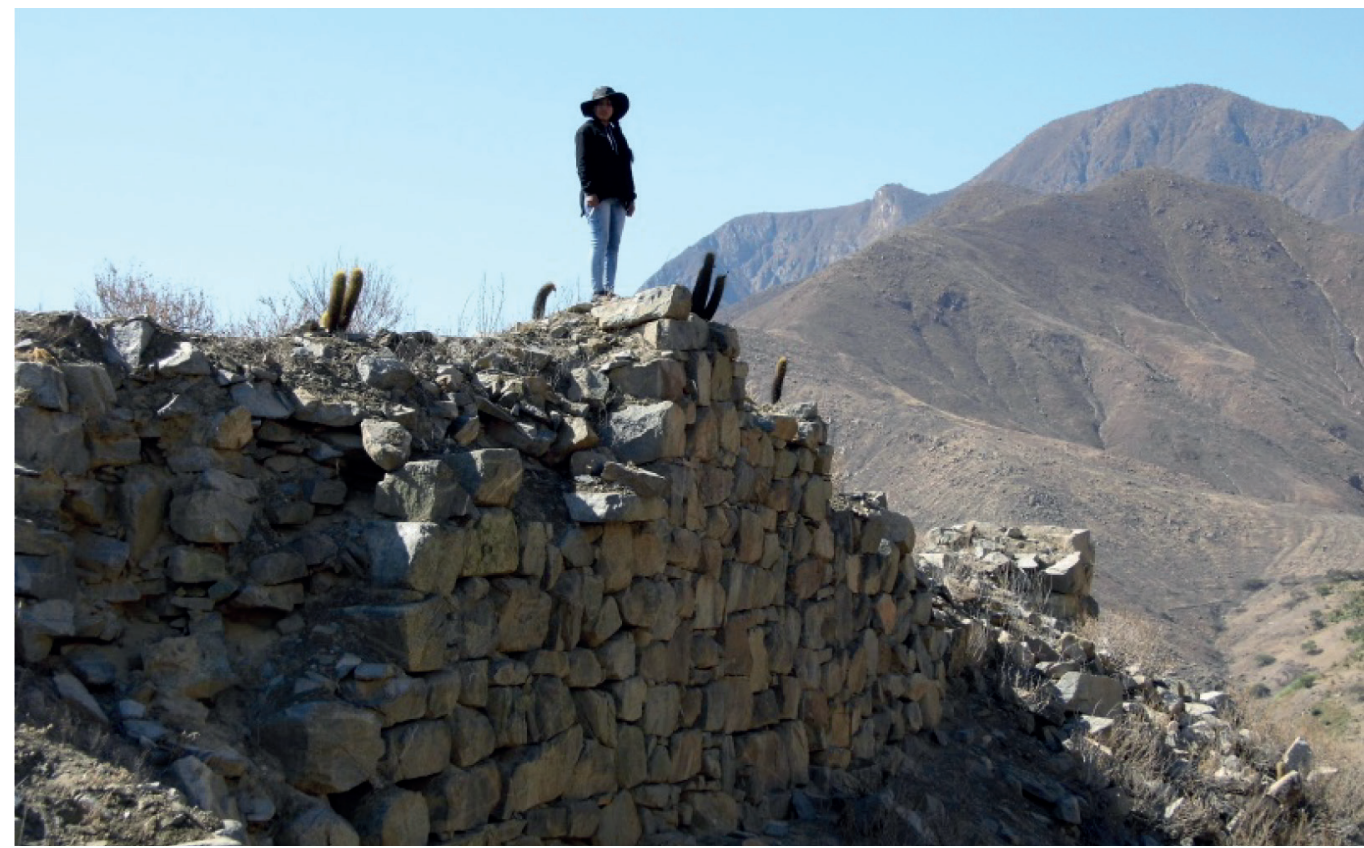

Figura 18.

Vista

panorámica de la muralla 1.

que muchas de estas estructuras están por debajo del nivel de la plataforma (semisubterráneos). En el lado este, podemos observar cabeceras de muros al nivel superficial de las terrazas. La técnica constructiva de estas estructuras fue elaborada con piedras canteadas de menor tamaño y más achatadas, unidas con mortero de barro (distinto a lo que se puede observar en los muros de la muralla), presentan muros dobles de unos 0.80 metros ancho, en algunos casos conserva más de 1 metros de alto.
La segunda plataforma también presenta muros grandes que sostiene un espacio en la parte superior. Estos muros tienen las mismas características de la primera muralla, en este caso la altura mejor conservada llega a 1.30 metros de alto y el ancho a 1.40 metros. El 90 \% de este amurallamiento se encuentra colapsado. En la parte superior se han construido estructuras cuadrangulares, adosadas a la muralla. Los muros construidos con piedras canteadas y mortero de barro, presentan doble hilera y pueden tener hasta 
vas y abrigos rocosos o sitios al aire libre, asociados a puntas de proyectil, correspondientes al Holoceno Temprano (10 $000-8000$ A.P.) y al Holoceno Medio (8 000 - 4000 A.P.), ubicados en la región Puna (Cruz 2018, Cruz, Sante y van Berkel 2016). Muchos de estos sitios están asociados a pinturas rupestres con representaciones variadas de camélidos, motivos geométricos, espirales, círculos y personajes, estando estos sitios ocupados por largos periodos de tiempo, incluso hasta el Formativo (Ambrosino 2017, 2019, van Dalen 2018, van Dalen, Allende y Obregón 2019, van Dalen, Huashuayo y Huamaní 2016, van Dalen, Obregón y Allende 2015), formando parte de una tradición rupestre que se extendió hasta cuencas vecinas como el Alto Pativilca (van Dalen, Obregón, Carhuas, Huamaní y Palomino 2019).

En el valle bajo y medio, durante el Arcaico Tardío (hacia 3000 a.C.), surgen sociedades complejas, formando parte de una extensa tradición religiosa que dio como resultado el surgimiento del Estado y la civilización andina, con su centro en la ciudad de Caral en el valle medio del río Supe (Shady 1997, 2006, 2009, Shady, Cáceda, Crispín, Machacuay, Novoa y Quispe 2009). En el valle bajo de Fortaleza están los sitios de Huaricanga, Caballete, El Porvenir, Shaura, entre muchos otros que corresponden a esta civilización (Ruiz, Creamer y Haas 2007).

En el periodo Formativo Temprano (hacia 1500 a.C.) surgen otros asentamientos complejos con arquitectura monumental. En la sección media y baja de esta cuenca del Fortaleza, Rafael Vega e investigadores (Vega, Villacorta, Cáceres y Marcone 1998: 222-223) registraron 30 sitios con arquitectura monumental perteneciente a este periodo: Racapampa, Limonpampa, Púlpito, Llama Rumi, Hornillos, Coricoto, Huaquish, Chasquitambo, Siki Rumi, Cerro Baúl, Mandahuás, Maray Colca, Huáncar bajo, Anta, Shaura Norte, Shaura Sur, Quilca Bajo, Cerro la Cruz, Montegrande, Huaricanga Norte, Huaricanga Sur, Castillo Huaricanga, Huaricanga Oeste, Tunán, Cerro Blanco Norte, Cerro Blanco Centro, Cerro Blanco Sur, Caballete, Cerro Lampay y Porvenir; sitios conformados por plataformas aterrazadas, pirámides cuadrangulares, pirámides rectangulares y pirámides con cuerpo central y alas laterales (de disposición en "U"; así como también plataformas bajas, patios a nivel, patios cuadrangu- lares hundidos y patios circulares hundidos), (Vega 2010, 2017).

A este periodo corresponde el sector III del complejo arqueológico Colquioc, conformado por las estructuras piramidales, presentando plaza circular hundida, el cual es un patrón de otros sitios contemporáneos del valle medio y bajo del Fortaleza (Vega, Villacorta, Cáceres y Marcone 1998, Zapata 2007). Esta tradición de arquitectura compleja con este tipo de asentamientos de función ceremonial no es exclusiva de este valle, pues se la encuentra en otros valles contiguos al norte como Casma, Huarmey y Culebras. Es posible que la ocupación del sector III del Complejo Arqueológico Colquioc se haya iniciado desde el Arcaico Tardío, situación que podrá ser corroborada o no con futuras investigaciones con excavaciones.

De igual manera, los petroglifos identificados junto al Pueblo Viejo de Colquioc corresponden a mediados o finales de este periodo Formativo, presentan motivos asociados con los motivos "chavinenses" hallados en sitios como Checta en el valle del Chillón (Echevarría 2014, 2015), así como el identificado en el sitio de Ichoca Marca frente a Raquia (van Dalen, Allende y Obregón 2019: 137), entre otros. La ubicación de Colquioc, junto a la desembocadura del río Purísima (de gran longitud) al río Fortaleza, le dio una importancia estratégica a esta zona donde se realizaban interacciones culturales entre diversas comunidades a través del "tinkuy", por ello la confluencia de tradiciones culturales costeńas y altoandinas. El tinkuy es la complementariedad de un sistema dual o tripartito, de desarrollo segmentario, cuyos integrantes tienen estrecha relación en el universo social y con relaciones complementarias de carácter social y religioso, representado por el yanantínk o la unión de dos ríos tributarios importantes, lugar donde se realizaba estos encuentros (Mallma; 2018: 56-57).

El siguiente periodo cultural identificado en nuestras investigaciones en Colquioc corresponde al periodo Estados Regionales (1100-1470 d.C.), se ha registrado áreas funerarias intrusivas con presencia de cistas funerarias en los tres sectores del complejo arqueológico Colquioc. Por su parte, el sitio Castillejo también data de este periodo, correspondiendo a un pucara o un sitio de control administrativo, encargado de regular las relaciones entre los pueblos de la 
cultura Cajacay que se desarrolló en la cuenca alta del río Fortaleza en su margen derecha (van Dalen 2007, 2013, 2017a, 2017b, 2019, van Dalen, Allende y Obregón 2019) con los numerosos pueblos del valle bajo y valles contiguos (Tabío 1977), entre los cuales interactuaban cultural y económicamente. En este periodo este territorio de Colquioc formó parte de la cultura Cajacay2, definida y caracterizada en anteriores estudios (van Dalen 2019, van Dalen, Allende y Obregón 2019). El sitio arqueológico Castillejo se mantuvo vigente hasta el Tawantinsuyu, pues se halló en superficie algunos fragmentos de estilo Inca Local. Las características del sitio de Castillejo son comunes para el periodo de Estados Regionales, con murallas defensivas circundantes para evitar ataques de sus vecinos; pues se trata de un periodo de constantes conflictos interétnicos por el control de los recursos. Aunque no existen fuentes etnohistóricas que lo señalen, es muy posible que esta sección del valle Purísima y el valle medio del río Fortaleza haya estado durante periodos prehispánicos tardíos, cultivado de cocales, como lo señalan las fuentes etnohistóricas para el vecino valle de Pativilca, entre las provincias actuales de Barranca y Ocros, donde existían chacras de coca destinado al culto de las huacas locales: "Coca es tambien ordinaria ofrenda, unas veces de la que ellos crian o compran, y las mas cogida de las chacaras, que llaman de las guacas, que para este efecto cultivan y labran de comunidad, y dos leguas del pueblo de Caxamarquilla, orilla del rio Huamanmayu, que es el mismo de la Barranca (porque no se da la coca sino en tierra muy caliente) habia catorce chacarillas de coca, que eran de todas las guacas de los pueblos de la sierra, y tienen indios que las guardan y cogen la coca y la llevan a los ministros de las huacas a sus tiempos, porque es universal ofrenda a todas las guacas y en todas ocasiones. Estas chacaras se mandaron quemar todas." (Arriaga; 1621: capítulo IV).

2 La cultura Cajacay que se desarrolló durante el periodo de Estados Regionales presenta características culturales uniformes en la margen izquierda de la cuenca alta del río Fortaleza, abarcando los territorios de los actuales distritos de Cajacay, Antonio Raymondi y Colquioc. Sus asentamientos se encuentran ubicados a diferentes altitudes con respecto al fondo del valle, desde las terrazas aluviales laterales a los valles hasta la cima de los cerros más elevados, aprovechando recursos de diversos ecosistemas. Sus pueblos se encuentran circundados por murallas perimétricas con arquitectura a base de piedras canteadas que conforman recintos de planta cuadrangular e irregular, con áreas funerarias al interior de estos pueblos o en áreas aisladas.
Durante el recorrido de Hernando Pizarro hacia Pachacamac en enero de 1533 con 14 españoles a caballo y 10 a pie, llegó el día 25 de enero al pueblo prehispánico de Marca, recorriendo al día siguiente el tramo hasta llegar a dormir al pueblo de Guaricanga, para llegar al día siguiente al pueblo de Perpunga (hoy Paramonga) para seguir por la Costa hacia Pachacamac. En el trayecto realizado el día 26 de enero de 1533 entre los pueblos de Marca y Guaricanga, los españoles pasaron por Chasquitambo. El camino prehispánico que desciende desde Marca y las alturas de Huayllapampa desciende por la margen derecha del río marca para unirse al valle de Fortaleza a 23 kilómetros río arriba del actual pueblo de Chasquitambo, punto donde se unía con el camino de penetración que se dirigía desde la Costa hacia Conococha y unirse al Qhapaq Nan, descendiendo por este camino (Del Busto 1967, Elías 2005: 45).

Tras la invasión española se establece el sistema de repartimientos y encomiendas, para desarrollarse en la segunda mitad del siglo XVI las reducciones de pueblos, despoblándose los antiguos poblados andinos para la fundación de pueblos hispanos dispuestos en patrón de damero. Uno de estos casos es el Pueblo Viejo de Colquioc, pueblo reduccional Colonial que se fundó con la reducción de los antiguos pueblos prehispánicos de la zona (entre estos Castillejo), fundado bajo la advocación de San Juan Bautista de Colqueyoc, con su plaza central y su iglesia mediana junto a esta. En los primeros días del mes de agosto de 1593 fue visitado por el arzobispo de Lima Toribio de Mogrovejo, quien lo describe como: "El pueblo de San Juan bautista de Colqueyo de esta doctrina [de San Agustín de Cajacay] está tres leguas del pueblo de Guaylacallan, de mal camino; es chaupi yunga. Hay en el 24 indios tributarios y 3 reservados y 78 de confesión y 116 ánimas. Tiene la iglesia de este pueblo 64 cabezas de ganado ovejuno, chicas y grandes" (Benito 2005: 10). Desde estos pueblos organizados en curatos, entre finales del siglo XVI y XVII se realizaron las campańas de extirpaciones de idolatrías para destruir las huacas locales, imponiendo la religión cristiana (Pereyra 1989, Robles 2005, van Dalen y Obregón 2016). Joseph de Arriaga refiere haber encontrado y destruido muchas huacas en la jurisdicción de este pueblo, como en Quepas donde se encontraba la huaca Huamantucoc, en Cocha Libiac donde se en- 
CuAdro 1: Cuadro cronológico por periodos (Lumbreras 1969, Casaverde 2007) con la asociación cronológica de cada sitio arqueológico identificado en Colquioc

\begin{tabular}{|c|c|c|}
\hline Periodo & Año de inicio & Sitios arqueológicos identificados en Colquioc \\
\hline Lítico & 13000 a.C. & \\
\hline Arcaico & 7000 a.C. & \\
\hline Formativo & 2000 a.C. & $\begin{array}{l}\text { Complejo Arqueológico Colquioc } \\
\text { (Sector III). } \\
\text { Complejo Arqueológico Colquioc } \\
\text { (Sector I: petroglifos). }\end{array}$ \\
\hline Desarrollos Regionales & 200 a.C. & \\
\hline Imperio Wari & 500 d.C. & \\
\hline Estados Regionales & 1100 d.C. & $\begin{array}{c}\text { Castillejo (Fortaleza Punta) } \\
\text { Complejo Arqueológico Colquioc } \\
\text { (Sectores I, II y III: contextos funerarios). }\end{array}$ \\
\hline $\begin{array}{c}\text { Imperio Inca } \\
\text { (Tahuantinsuyo) }\end{array}$ & 1450 d.C. & Castillejo (Fortaleza Punta) \\
\hline $\begin{array}{l}\text { Colonial Temprano o de } \\
\text { Transición Inca - Colonial }\end{array}$ & 1532 d.C. & Castillejo (Fortaleza Punta) \\
\hline Colonial Medio & 1570 d.C. & $\begin{array}{c}\text { Complejo Arqueológico Colquioc } \\
\text { (Sector I: Pueblo Viejo de Colquioc). }\end{array}$ \\
\hline Colonial Tardío & 1700 d.C. & \\
\hline
\end{tabular}

contraba el ídolo Mullu Cayán y su hermano Coto Tumac, entre otros (Arriaga 1621: 100-101). Existen numerosos documentos en archivos nacionales y regionales referidos a la historia de Colquioc a través de la Colonia y la República (Chucho 2020). Este Pueblo Viejo de Colquioc estuvo habitado hasta la segunda mitad del siglo XVIII en que la población será trasladada al nuevo pueblo de Colquioc.

Muchos de los actuales pueblos y ciudades andinas fueron fundados en la segunda mitad del siglo XVI y han seguido siendo ocupados hasta la actualidad de manera ininterrumpida. Algunos otros pueblos por diversos motivos fueron abandonados durante el transcurso de la Colonia o la República, al verse afectados por desastres naturales (como Yungay en el Callejón de Huaylas o el cercano pueblo de Yamor en la cuenca del alto Fortaleza, devastados por el sismo de 1970), por la migración de la población hacia un emplazamiento más cercano a las áreas productivas (agrícolas o ganaderas) o por la despoblación debido a la migración de sus habitantes o muerte por enfermedades. Un caso similar al del Pueblo Viejo de
Colquioc es el de Maray Viejo en la cuenca del río Checras (Noriega 2015), pues su fundación se dio en un área de ocupación prehispánica, dándose una continuidad ocupacional hasta el siglo XVIII.

Estos pueblos de patrón constructivo hispano (con patrón ajedrezado y ortogonal, con disposición en manzanas alrededor de una plaza central donde se ubica a un lado la iglesia), difieren de aquellos pueblos de patrón andino, los cuales siguieron siendo ocupados en su mayoría hasta mediados del siglo XVI; pero que entre 1532 y 1550-70 sufrieron una ligera variación en su configuración con la adaptación o construcción de edificaciones para la administración política y religiosa española. Así, muchas Kallankas Incas van a ser acondicionadas para que funcionen como iglesias, como se ha reportado en diversas regiones de los Andes como en Caraybamba en Apurímac (van Dalen 2011), Nieve Nieve en el valle medio de Lurín (Negro y Fuertes 1989), Maray Viejo en la cuenca del río Checras (Noriega 2015), Lumbra en el valle medio del río Chancay (van Dalen 2014), entre muchos otros. 


\section{Conclusiones}

Los trabajos de prospección arqueológica desarrollada en el ámbito del distrito de Colquioc han permitido identificar en el anexo de Colquioc una gran densidad de evidencias arqueológicas, correspondientes a diversos periodos culturales como el Formativo, Estados Regionales y Colonial Temprano o Periodo de Transición Tawantinsuyu Colonial. Se ha identificado arquitectura monumental del periodo Formativo, conformado por un conjunto con forma de "L" y una plaza circular hundida, así como una pirámide de tres plataformas. Además, los petroglifos o quilcas identificadas presentan motivos de estilo chavinoide. Durante el periodo de Estados Regionales esta zona formó parte de la cultura Cajacay, gozando geopolíticamente de una ubicación privilegiada, mediando las relaciones entre las sociedades altoandinas y las costeñas. Tras la invasión española, se fundó el Pueblo Viejo de Colquioc, en el cual fue asentada la población reducida de los pueblos prehispánicos de la zona. La zona de Colquioc, por su ubicación junto a la confluencia de los ríos Fortaleza y Purísima, fue una zona de gran importancia geopolítica desde periodos prehispánicos tempranos, evidenciada en la presencia de áreas ceremoniales donde se realizaban encuentros religiosos y de interacción social entre poblaciones de diversas regiones a través del "tinkuy", siendo además, lugar de tránsito obligado a las personas que se desplazaban desde el sur de Ancash a la Costa.

\section{Reconocimientos}

Nuestro reconocimiento a la Municipalidad Distrital de Colquioc, a través de su alcalde Don Guillermo Carlos Pariasca Dextre y su equipo de regidores por el apoyo brindado. De igual manera un especial agradecimiento a la gerenta Municipal Doña Isabela Yudy Díaz León. Los estudiantes de arqueología de la UNMSM que apoyaron en las prospecciones arqueológicas fueron Noelia Alca Aiquipa y Víctor Medina Torres. De igual manera, los trabajos fueron posibles gracias al apoyo del profesor Raúl Chucho Torrez, del colegio de Chasquitambo.

\section{Bibliografía}

Ambrosino, Gordon (2017). Rock Art, Ancestors and Water: The Semiotic Construction of Landscapes in the Central Andes. Tesis para optar el grado de Doctor en Antropología. Departamento de Antropología, Universidad Los Andes. Bogotá, 2 volúmenes.

Ambrosino, Gordon (2019). Inscription, Place, and Memory: Palimpsest Rock Art and the Evolution of Highland, Andean Social Landscapes in the Formative Period (1500-200 BC). H-ART. Revista de historia, teoría y crítica de arte, 5: 127-156.

Arriaga, Pablo Joseph (1999 [1621]). La extirpación de la idolatria en el Piru. Centro Bartolomé de las Casas. Cusco.

Benito, José (2006). Libro de visitas de Santo Toribio de Mogrovejo (1593-1605). Fondo Editorial Pontificia Universidad Católica del Perú. Lima, 446 pp.

Casaverde Ríos, Guido (2007). Periodo de Transición. Colonial vs Inca: el caso d ela sierra de Lima. Kullpi. Investigaciones culturales en la provincia de Huaral y el Norte Chico, 3: 317-326. Lima.

Cruz Quiñonez, John (2018). Asentamientos de cazadores-recolectores del Holoceno Temprano y Medio en la sierra sur de Ancash". Actas del III Congreso Nacional de Arqueología: 255-259. Ministerio de Cultura. Lima.

Cruz, John; Sante, Eduardo; y Van Berkel, Stephanie (2016). Ocupaciones humanas tempranas durante el periodo Arcaico en la puna sur de Ancash: El sitio de Hatun Machay. Arqueología de la sierra de Ancash: Población y territorio: 13-28. Bebel Ibarra, editor. Instituto de Estudios Huarinos. Lima.

Chucho Torrez, Raúl (2020, en prensa). Colquioc a través de la historia. Municipalidad Distrital de Colquioc. Lima.

Del Busto Duthurburu, José A. (1967). La expedición de Hernando Pizarro a Pachacamac. Humanidades, 1: 63- 86. Pontificia Universidad Católica del Perú. Lima.

Echevarría López, Gori Tumi (2014). Arte rupestre en la yunga del río Chillón, nuevos planteamientos. Arqueología de las cuencas alto y medio andinas del departamento de Lima: 301-312. Pieter van Dalen, editor. Universidad Nacional Mayor de San Marcos. Lima.

Echevarría López, Gori Tumi (2015). Secuencia y cronología de las quilcas o arte rupestre de Lima. Tesis para optar el título profesional de Licenciado en Arqueología. Facultad de Ciencias Sociales, Universidad Nacional Mayor de San Marcos. Lima. 
ElíAs IpInZE, Jesús (2005). La antigua provincia de Chancay, siglos XVI-XVIII. Huacho.

Lumbreras Salcedo, Luis (1969). De los pueblos, de las culturas y las artes del Antiguo Perú. Lima, 379 pp.

Mallma Cortéz, Arturo (2018). El simbolismo del Tinkuy en la cerámica de la cultura Xauxa. Tesis para optar el grado de Magíster en Arqueología Andina. Universidad Nacional Mayor de San Marcos. Lima.

Negro, Sandra y fuertes, María (1989). Nieve Nieve, Arquitectura y Urbanismo en la Costa Central del Perú. Boletín de Lima, 62: 57-71. Lima.

NoriegA, Aldo (2015). Excavaciones arqueológicas exploratorias en Maray Viejo. Un asentamiento colonial en la región de Checras. Arqueología y Sociedad, 29: 339364. Universidad Nacional Mayor de San Marcos. Lima.

Pereyra Plascencia, Hugo (1989). Chiquián y la Región de Lampas entre los siglos XVI y XVII: una hipótesis sobre el origen de las campañas de extirpación de idolatrías en el Arzobispado. Boletín del Instituto Riva Agüero, 16: 21-54. Pontífice Universidad Católica del Perú. Lima.

Robles Mendoza, Román (2005). Las iglesias andinas: huellas de la cristianización y religiosidad popular". Revista de Antropología, 3: 103-162. Cuarta época. Universidad Nacional Mayor de San Marcos. Lima.

Ruiz Rubio, Álvaro; Creamer, Winifred; y HaAs, Jonathan (2007). Investigaciones arqueológicas en los sitios del Arcaico Tardio (3000 a 1800 años a.C.) del valle de Pativilca, Perú. Instituto Cultural del Norte Chico. Lima, 129+ pp.

SHADY, Ruth (1997) La ciudad sagrada de Caral - Supe en los albores de la civilización en el Perú. Universidad Nacional Mayor de San Marcos. Lima, 31 pp.

SHady, Ruth (2006). La civilización Caral: sistema social y manejo del territorio y sus recursos. Su trascendencia en el proceso cultural andino. Boletín de Arqueología PUCP, 10: 59-89. Pontificia Universidad Católica del Perú. Lima.

Shady, Ruth (2009). Caral, Supe: La civilización más antigua de América. Investigaciones Sociales, 9: 51-81. Universidad Nacional Mayor de San Marcos. Lima.

Shady, Ruth; CÁCedA, Daniel; Crispín, Aldemar; Machacuay, Marco; NovoA, Pedro; Quispe, Edna (2009). Caral. La civilización más antigua de las Américas: 15 años develando su historia. Zona Arqueológica Caral-Supe / Ministerio de Cultura del Perú. Lima.
Tabio, Ernesto (1977). Prehistoria de la costa del Perú. Academia de Ciencias de Cuba. La Habana. 267 pp.

Van Dalen Luna, Pieter (2007). Palpin: un asentamiento con arquitectura funeraria en el alto Fortaleza, Cajacay, Ancash. Tukuy Rikuq, 4: 51-57. Lima.

Van Dalen Luna, Pieter (2011). Arqueología prehispánica tardia de Caraybamba, Aymaraes, Apurimac. Asentamientos $y$ andenerías. Universidad Nacional Mayor de San Marcos. Lima.

Van Dalen Luna, Pieter (2013). San Ignacio, un sitio arqueológico tardío en Yamor, distrito de Antonio Raymondi, provincia de Bolognesi, Ancash. Tiempos. Revista de historia y cultura, 8: 107-122. Lima.

Van Dalen Luna, Pieter (2014). El Periodo de Transición Tawantinsuyu-Colonial o de Desestructuración andina en el complejo arqueológico de Lumbra, valle medio del río Chancay-Huaral. Lima Subterránea. Arqueología histórica. Criptas, bóvedas, canales virreinales y republicanos: 29-56. Richard Chuhue y Pieter van Dalen, editores. Universidad Nacional Mayor de San Marcos. Lima.

Van Dalen Luna, Pieter (2017a). Los periodos prehispánicos tardíos en Raquia y Yamor: una aproximación a la comprensión del Intermedio Tardío (1000 - 1470 d.C.) desde San Ignacio, Ancash. XXI Encuentro Regional de Escritores y Poetas de Ancash. Revista Cultural de Ancash AEPA, 5: 37-49. Huaraz.

Van Dalen Luna, Pieter (2017b). San Ignacio. Un sitio de la cultura Cajacay en Yamor, Bolognesi (800-1535 d.C.). Panorama Regional, 8: 50-51. Lima.

Van Dalen Luna, Pieter (2018). Pila Punta: la joya de Pararín. Panorama Regional, 9: 15-17. Lima.

Van Dalen Luna, Pieter (2019). La cultura Cajacay, entidad sociopolítica del periodo Intermedio tardío (10001470 d.C.) del sur de Ancash. Palabras ancashinas al viento: 14-24. Asociación de escritores ancashinos. Lima.

Van Dalen Luna, Pieter; Allende Joaquín, Daniel y Obregón Pillaca, Hamilton (2019). Arqueología de Raquia y Yamor, distrito de Antonio Raymondi, provincia de Bolognesi, departamento de Ancash: cuenca alta del rio Fortaleza. Nuevos datos para la comprensión de la arqueologia del sur de Ancash. Lima, 168 pp.

Van Dalen Luna, Pieter y Huashuayo Casavilca, Yesenia y Huamaní Perlacios, Joe (2016). El hallazgo de nueve sitios arqueológicos con quillcas en Cajacay, BolognesiAncash. Arqueología y Sociedad, 31: 471-494. Museo 
de Arqueología y Antropología, Universidad Nacional Mayor de San Marcos. Lima.

Van Dalen Luna, Pieter y Obregón Pillaca, Hamilton (2016). La fiesta de San Bernardo de Yamor y la participación del Inca con las Pallas, Bolognesi Ancash". Cultura y Folclore en el Perú. A 100 años del nacimiento de José María Arguedas: 369-389. Carlos Sánchez Huaringa, editor. Centro Universitario de Folclore, Centro Cultural, Universidad Nacional Mayor de San Marcos. Lima.

Van Dalen Luna, Pieter; Obregón Pillaca, Hamilton; Allende Joaquín, Daniel (2015). El arte rupestre de Yamor, cuenca alta del río Fortaleza, BolognesiAncash. Arqueología y Sociedad, 29: 407-461. Museo de Arqueología y Antropología, Universidad Nacional Mayor de San Marcos. Lima.

Van Dalen Luna, Pieter; Obregón Pillaca, Hamilton; Carhuas Tenorio, Héctor; Huamaní Perlacios, Joe y Palomino Gutierrez, José Luis (2019). Quilcas en la cuenca alta del Río Aynín (Pativilca), provincia de Bolognesi - Ancash. Recientes investigaciones sobre sitios con quilcas o arte rupestre en el Perú: 26-46. Pieter van Dalen, editor. Lima.

Vega Centeno, Rafael; Villacorta, Luis; Cáceres, Luis; Marcone, Giancarlo (1998). Arquitectura monumental temprana en el valle medio de Fortaleza. Boletín de arqueología PUCP, 2: 219-238. Lima.

Vega Centeno, Rafael (2010). Cerro Lampay: Architectural design and human interaction in the North Central Coast of Perú. Latin American Antiquity, 21: 115-145.

Vega Centeno, Rafael (2017). Detrás de los Paramentos. Organización de la Construcción en Cerro Blanco Sur, un Edificio Temprano de Los Andes Centrales (Perú). Chungara, 49: 529-553. Arica.

Zapata Huamaní, Carlos (2007). Cerro Blanco Sur: arquitectura del Formativo temprano en el valle de Fortaleza. Kullpi. Investigaciones culturales en la provincia de Huaral y el Norte Chico, 3: 279-290. Huaral.

Zubieta Núñez, Filomeno (2003). Por la ruta del Huayhuash. Los recursos Turisticos de la provincia de Bolognesi. Huacho, 150 pp. 